was easily accomplished in the following manner:-A mattras having been placed upon the floor of the theatre, the patient was made to lie along it on his left side. The body was fixed by means of a round towel, passed underneath the perineum, and fastened to a screw ring in the boards at a little distance beyond the patient's head, the pulleys being fixed to a similar ring also in the floor, at about the same distance from his feet. A band was now buckled round the lower part of the thigh, previously covered with a wetted bandage, and attached to the nearest hook of the pulley. A gradual and steady extension was then made, and kept up for about five ninutes, the injured limb being thus drawn downwards, in a direction partly across and in advance of the other. As soon as the head of the bone had been drawn as far as the upper edge of the acetabulum (which was discoverable to the feel) I placed a towel under the upper part of the thigh, and, taking both ends in my hands, drew this part of the bone outwards, while an assistant, at the same time, rotated the limb rather forcibly inwards. After using these means for about two minutes, any further extension by the pulleys having duriug this time been suspended, the head of the bone suddenly returned into the acetabulum with the usual noise, followed by an almost immediate restoration of the functions of the joint. He could shortly after, while lying in his bed, perform all the ordinary movements of the joint with tolerable ease.

22. He complained of pain and tenderness over the surface of the abdomen. with constipation, and other signs of commencing peritonitis, stiffness of the jaw, and muscles about the neck; and, as I conceived that trismus might possibly ensue in consequence of the injury to the ligamentous texture of the joint, (although a rare occurrence,) I requested that he might be transferred to the physician. Hot-bath at $100^{\circ}$, and fomentations containing opium to the neck.

31. The warm-bath and fomentation relieved the stiffness of the jaw and muscles of the neck, but he suffered severely from peritonitis, (for which leeches were repeutedly applied,) tollowed by diarrhca, which has greatly weakened him. He walked a little on the injured limb, for the first time since the reduction.

Sept. 24. He had gradually recovered from the state of debility into which he had been brought by the diarrhœa, and as he had entirely regained the use of the limb, and could walk about the ward without any pain, he was discharged from the hospital, and made an out-patient.

REM ARRs.- It will be seen that the appearances in this case differed in almost every particular from those which are usually observed in ordinary cases of dislocation of the feinur on the dorsum ilii. The singularly bulged and rounded appearance of the joint, the entire absence of inversion, and the difficulty of distinguishing the head of the bone in its new situation, are circumstances which I do not recollect having been mentioned by any author who has written on this subject. It struck me, at the time, that the head of the bone had become in some way entangled in the torn capsular ligament, and that so the trochanter was prevented rolling inwards, and producing the inversion which commonly takes place. The reduction was accomplished in the manner directed by Sir A. Cooper, with the exception only that the head of the bone, on approuching the rim of the acetabulun, was rotated inwards instead of outwards, as enjoined by that distinguished surgeon.

How far the symptoms of trismus might be said to depend upon the injury inflicted on the capsular ligament by the extension of the bone, and the stretching of the tenduns, insertointo the root of the trochanter, I am not prepared posay? but I should think it not improbable they might coury in very severe case of this description, although I and ingere that any instance of the kind has been recontiod The circuinstance of peritoneal inflammation ogary 8 o shortly after the reduction is very remarke.

\section{REPORT OF THE ROYAL COLLEGE OF SURGEONS OF EDINBURGH,}

ON MESSRS. WARBURTON'S ANE HAWES'S BILLS. Adopted unanimously, Dec. 12, 1840.

Is our 13th number we publisled an analysis of the first part of this Report. In the second part, the College furnish a tabular view of the several provisions of Messrs. Hawes's and Warburton's bills, and then offer the following commentaries on them:-

The preamble of Mr. Hawes's draft makes no allusion to the subject of education. The college would recommend the insertion, after 'the same shall be' (vide the 5th rine), of the following words, ' $d u_{1} y$ instructed in the several departments of medicine, and,' c.

The $2 \mathrm{~d}$, or interpretation clause, is much simpler than the corresponding one in Mr. Warburton's bill, and it appears to be sufticiently precise for all useful purposes.

By clauses 3,12 , and 13 , the appointment and removal of the registrars are regulated. These functions are committed to the medical councils. except in the first instance after the passing of the act, when the registrars are to be nominated by one of the secretaries of state. The College are of opinion that their nomination and removal ought to be permanently lodged with the responsible ninisters of the crown, as proposed by Mr. Warburton, in order to afford a security to the public for the efficient administration of the act; and that the registrar ought not to be a person engaged in medical practice.

The registration of medical practitioners, proposed in the $4 \mathrm{th}, 5 \mathrm{th}$, and $32 \mathrm{~d}$ clauses, is a most desirable and necessary measure, and is less complex in Mr. Hawes's scheme than in the other. Mr. Warburton proposes to enrol persons practising the healing art without having any qualification, as well as those who have it, but in separate lists. This appears to the College unnecessary, and undesirable, as giving a species of encouragement and countenance to unqualitied persons, at which presumptuous ignorance and unpriticipled selfishness would eagerly grasp. If the quali. fied men only be registered, the public will draw the proper inference as to the others. It is an additional disadvantage of this part of Mr. Warlurton's arrangements, that it makes necessary a very complicated and expensive apparatus of sub-registrars. As it often happens that diplonuas are lost, it will be necessary to provide that the production of certificates, properly attested, of their diplomas having been granted, shall entitle the parties to be registered in such cases.

The 4th clause of Mr. Hawes's draft is evidently designed to place the present race of practitioners, holding diplomas and licenses, exactly on the same fouting, as to privilege, with those who shall be licensed under the provisions of the draft $(\mathrm{Cl} .32)$, both classes of practitioners having been previously registered in term:s of the $4 \mathrm{th}$ and 5 th clauses. As this is a matter of very great importance, it is desirable that it should be so expressed as to leave no possibility of doubt respecting the purpose of the act; and this may be done by adding to the clause the following words:- But that each registrar shall grant such certificates, or such licenses, although the diplomas, certificates, or licenses produred by the. applicants may have been granted by boards whose present powers of licensing do not extend to that part of the kingdom for which the said registrar is appointed to act.'

It appears to the College that the payments for registration, proposed under the 5th clause, ought to be as small as they can be made consistently with the efficiency of the system. There are many medical men in small and illpaid practice, especially in rural districts, to whom even a small annual payment is of some importance; and when it is considered that the non-payment of the annual sum will infer the loss of qualification, it is obvious that a payment, which is needlessly large, would be a very great hardship to many such persons. 
The registration of medical students is a matter of importance altogether omitted by $\mathrm{Mr}$. Hawes, but introduced very properly into the bill of $\mathrm{Mr}$. Warburton $(\mathrm{Cl} .31,46)$. It appears to the College that a clause similar in principle to the 3 I st clause of the bill of Mr. Warburton ought to be enatted; that is to say, a cluuse empowering the senate and the medical councils to frame bye-laws for the matriculation of students of medicine, and for the registration of their several classes. Mr. Warburton's 46th clause, prescribing the method of registration, seems unnecessarily and inconveniently minute. The College have for many years conducted such a register, and feel confident that no plan can be devised which will not be found, on actual trial, to require alterations and moditications to suit it to the circuinstances of each school, and to the changes of eystem which are perpetually occurring. It will be better, therefore, not to determine the detuils by parliamentary authority, but to leave them open to the consideration of the senate and of the councils, to whoin they may very cafely be intrusted.

In regard to the mode of electing a medical council for each portion of the $\mathrm{L}_{\text {uited }} \mathrm{Kingd}$ inn $(\mathrm{Cl} .6-20)$, and also in regard to the constitution of that council, there are material differences between the two proposals. Mr. Warburton's council of thirty-six appears to be ton large for practical efficiency. It seems still more objectionable in containing twelve members not of the profession. It appeare necessary that a council, whose oftice it is to superintend the practical working of the bill, should consist solely of those who are practically conversant with the state of the profession. Mr. Warburton also proposes to devolve on the council a most invidious and disagreeable task, that of determining which of their number ought to go out of office at each unnual period. In all these points the arrangements of $\mathrm{Mr}$. Hawes appear to the College to be preferable. His council, containing twenty councillors elected by the profession at large $(\mathrm{Cl} .6)$, besides a representative of each of the licensing boards (of which there are seven in Scotland, $\mathrm{Cl}$. 11), would be sufficiently numerous, perhaps too numerous, for actual business.

Mr. Warburton's plan is decidedly preferable, in proposing a rotation in the council $(\mathrm{Cl} .20)$; while $\mathrm{Mr}$. Hawes proposes to elect the council for three years $(\mathrm{Cl} .6)$, and theil dissolve it with a view to a complete new election. Perliaps the best way would be to allow the first council to sit for two years without alteration, and then change onethird of the whole annually. In this case each of the two classes of councillors ought to have its separate rotation.

The election, according to Mr. Hawes, is to take place (Cl. 9) 'before the registrur,' to which should be added, 'or a deputy authorised by him in case of illness or necessary absence.' It would also be more precise if, instead of stating $(\mathrm{Cl} .10)$ that 'the registrar shall publicly ballot,' it were enacted that he shall baliot 'before two cuuncillors appointed to superintend the election.'

There is all excellent proposal by Mr. Hawes ( $\mathrm{Cl} .7$ ), that candidates for the office of councillor should be regularly nominated before they can be balloted for; and it would be a great improvement on this proposal if the schedule for nominating them were so expressed, as to make it necessary for those who put them in nomination to ascertain that they are willing to act it elected.

The selection of the registrars by the councils $(\mathrm{Cl} 12)$ has been already objected to; and the remuneration of the councillurs for their attendance $(C l .14)$ ought to be subject to some public authority, such as that of ilie secretary of State for the Home Department, or the Lords of the Treasury, as proposed by Mr. Warburton.

Clause 15 requires the presence of a majority of the whole council to make their acts valid. This condition might be found so difficult in actual working, as to render the whole bill abortive. A smaller quorum (six, for in. stance, as proposed by Mr. Warburton) might suffice, and the regular attendance of councillors should be enforced by a penalty. It would also be well that loss of office were incurred by absence from a certain proportion of the meetings during the year (unless from the illness of the party), and that accurate minutes of all the transactions of the councils were kept (as proposed in Mr. Warburton's bill, Cl.21), containing lists of those present at each sederunt, and a fill account of all the res gesta.

Clause 17 proposes to place the surplus funds at the disposal of the councils and senate conjointly, for purposes connected with the advancement of medicine, and of medical science and literature. For reasons already assigned, the College are of opinion that the surplus should be applied to reduce the amount of the assessment for the succeeding years.

In concluding their remarks on the subject of the medical councils, the College must express their satisfaction with the proposal of Mr. Hawes to introduce into them representatives of the existing boards ( $\mathrm{Cl}$.11). The knowledge of the whole subject, which these representatives would bring with them, could not fail greatly to facilitate the transaction of the important business confided to the councils; while this moderate concession to those licensing medical incorporations, which have hitherto conferred medical qualifications, will be likely to disarm their opposition, and greatly to facilitate the progress of the measure.

Clauses 21-29, relating to the senate, are open to many of the remarks already applied to the councils. By Mr. Hawes's draft the members of the senate are to continue in office five whole years, which is evidently too long a tenure; while the complete annual change of the whole senate, proposed by Mr. Warburton ( $\mathrm{Cl}$. 24), would be inconsistent with any thing like unity of plan in any body 80 constituted. The number of members proposed by $\mathrm{Mr}$. Warburton, thirty-six, appears to the College to be by much too large; while Mr. Hawes's number, niue, is perhaps inconveniently small. The fine for non-attendance at each meeting, and the loss of office by not attending a certain proportion of the meetings, are as applicable here as in the case of the councils. The College are of opinion that the introduction into the senate of a few non-medical members appointed by the secretary of state, and impartially selected from the three divisions of the kingdom, would accumplish Mr. Warburton's object of securing the interests of the public. The functions of the senate being to secure unifornity of plan in the subordinate boards, and not, as in the case of the councils, to superintend details, the introduction of non-medical members into the former body seems free from objection. Three non-medical members added to the other nine, would make a sufficiently numerous senate. One of these three, and one member from each of the divisions of the kingdom, might retire annually, beginning after the lapse of the first two years. Of the three members sent to the senate from each of the councils, one should be a representative of one of the licensing boards.

The power of disallowing the bye-laws made hy the seluate ( $: l .28)$, proposed to be given to the privy council, would be another important security for these bye-laws being consistent with the public welfare. The College entirely approve of the existence of a chcck of this description, agreeing, as they do, in the opinion of Mr. Warburton, 'that in no profession or business is it safe for the state to intrust those who are engaged in that profession or business with the regulation of it, without interposing guards and checks of every kind, to prevent the trust from being turned to the advantage of the few, and to the disadvantage of the many.'

It appears to the College that clause 23 should be so altered, as to make it necessary for the senate to meet at certain periods in Edinburgh and in Dublin, as well as in London. The expenses of the senate should be defrayed out of a common fund contributed by the councils, or in the method provided by Clause 27, in which the expenses of travelling are, apparently without any good reason, excepted from its provisions. The method proposed in the draft 
would press with most severity on those councils most distant from the spot where the senate assembles.

Clause 25 should provide that the president, or person acting as such, should have both a vote and a casting vote, as in the councils.

Clause 28 confers powers on the senate to make byelaws for regulating medical education. It appears to the College, that there are two points relating to the subject of this clause which are so important, that the senate should not merely be empowered, but enjoined, to provide for them in their bye-laws. The first of these is the fixing a minimum course of education, without which no candidate should be examined before any board for a medical qualification. A minimum should also be fixed, to qualify for the license of chemist or druggist. The other point required to be provided for is, the qualification of medical schools and of medical teachers, which it is very necessary should also be distinctly defined, and made universal in its application to all the boards for examining candidates. The scrutiny of the course of study should be made by some officer acting under the authority of the councils, who should, after satisfying himself that it is complete, grant a certificate to that effect, addressed to the examining buard.

Clause 29 should be so expressed, as to authorize and require the senate to appoint proper persons to prepare a Pharmacopcia.

The College cannot but regard it as a great defect in $\mathrm{Mr}$. Warburton's arrangements, that in calling into existence a class of practitioners, for whose efficiency they propose to afford a sufficient guarantee to the public, they leave the present system of licensing practitioners, with whatever imperfections there may attach to it, untouched. If there be any of the licensing boards which, for the sake of increasing the number of candidates for their license, require a less complete course of education, or enforce a less rigorous system of examination than would be requisite to insure the safety of the public, there is no provision in Mr. Warburton's bill for the abatement of the evil. The licentiates of these bodies will not, indeed, enjoy the universal right of practice conferred on the fellows of the New College, but within certain boundaries their right of practice will continue as at present. Indeed, instead of providing for the remedying of the evils of the present system, a temptation is rather held out by the proposed arrangements to these bodies still farther to reduce their standard of education, and still farther to relax the severity of their examination, as some compensation to candidates for their licenses, in lieu of the more extended rights which the fellowship of the New College is to confer.

As it does not appear that any public benefit can arise from this part of Mr. Warburton's plan, it may be presumed that it is intended as a boon to the existing boards; but if such be its intent, a boon equally acceptable, and of a much less questionable character as regards the public interest, would be conferred in the adoption of that conjoint system of examination which the College have pointed out and recommended.

Mr. Hawes proposes ( $\mathrm{Cl} .32$ and 37) to establish only one grade of qualification as respects the practice of the profession in all its departments; $\mathrm{Mr}$. Warburton proposes several gradations of privilege. The College greatly prefer the first of these arrangernents.

It appears to the College to be a defect of Mr. Hawes's draft that no designation, except that of "medical practitioner," is given to those who receive the license. A more characteristic designation would be useful merely as a distinctive mark, and it should be such as to convey to the public the idea of merit and of eminence. Some such title as "Fellows of the College of Medicine of the United Kingdom" would serve these important ends.

The College of Medicine proposed in the bill of $\mathbf{M r}$. Warburton ( $\mathrm{Cl} .29,30$, and 31 ) appears to be faulty in its constitution. The most respectable practitioners now existing in this country could not obtain admission to it, except by ballot. In all prior legislative changes, it has been usual to pay the greatest possible regard to the interests of such parties. They ought not merely to be protected in the enjoyment of their present privileges, but freely admitted, and that without the ordeal of the ballot or of fresh examinations, to that equality of professional advantages which it is the object of all reformers to secure to the whole medical profession.

Clause 36, relating to medical assistants of practitioners and of chemists and druggists, will require emendation. Subordinate assistants, who are not apprentices, are often employed in drug-shops and in the private laboratories of practitioners for the purpose of acquiring a knowlenge of the qualities of drugs, and of the arts of pharmacy and prescription. These are undoubtedly " assistants," and they are so circumstanced that they cannot possibly hold a qualification under the act. So long as they hold a decidedly suburdinate position, and act under the directions, and on the responsibility of the heads of the establishment, no injury can arise from this practice, any more than from employing apprentices. The case of partners and salaried superintendents acting on their own responsibility, is altogether different, and to them the clause may fairly be made applicable.

Clause 37 would be greatly improved by the addition of some such sentence as the following, which is nearly verbatim the 13th clanse of the bill of Mr. Warburton :"And no persons who do not possess certificates to practise the art of medicine shall be deemed capable of acting in any part of the United Kingdom in the capacity of a physician, surgeon, apothecary, surgeon-apothecary, accoucheur, or other medical officer, to any hospital, infirmary, dispensary, lunatic or other asylum, lying-in-hospital, gaol, penitentiary, house of correction, house of industry, parochial or union workhouse or poorhouse, parish, union, or other public establishment, body, or institution, or to any society for affording mutual relief in sickness, infirmity, or old age, nor in the capacity of a physician, surgeon, assistantsurgeon, or apothecary, to the British army or navy, or in the service of the East India Company." If the penalty for practising without a license be abrogated, in conformity with the suggestions of the college, it will be very necessary that this clause should be adopted.

The right to recover professional charges in courts of law, which it is the object of clause 38 to confer on the qualified practitioner, should not be given to the unqualified. For this reason the College propose to introduce after the word " medicine" (line 4th) the words " but for no others."

Clause 43, so far as it relates to practitioners, is inconsistent with what has been advanced in the prefatory part of this report. The College, therefore, would wish the whole of it to be omitted, except what relates to chemists and druggists. But they would propose as an amendment of the 41st clause, to introduce, immediately after the word "aforesaid" (line 11th,) the following words: " or shall fraudently assume any title belonging to those who are licensed under the act, without having acquired a legal right to the same."

There are some small matters, of little more than verbal importance, which are subjoined, as their introduction in their proper place would have interrupted the course of the remarks.

In clause 11 the designations of the Scottish licensing bodies will require to be differently worded. In some of the Universities there is no body known by. the name of the Faculty of Medicine; and the Colleges of Physicians and Surgeons, being possessed of popular constitutions, conferring on all their members equal rights, will claim the privilege of appointing their own representatives, instead of delegating that power to any council. The same remark is applicable to the constitution of the College of Surgeons in Ireland. The clause as it respects Scctland may be amended thus: "It shall be lawful for the Senatus Academicus in the Universities of Edinburgh, Glasgow, St. Andrews, and Aberdeen, and for the Royal College of Physicians and the Royal College of Surgeons of Edinburgh, 
and for the Faculty of Physicians and Surgeons of Glasgow," \&c. \&cc.

In clanse 16 the transposition of a sentence seems necessary to bring out the sense intended to be expressed. The words " at which a majority of the existing menbers of the council shall be present" (see lines 6 and 7 ,) should be brought in after the word "meeting" in line 8th.

In clause 32 , page 14, line 11 , the word "either" should be exchanged for "any one."

In clause 45 occurs the expression "Petty Sessions," a term not employed in Scotland. The clause may be aniended by the introduction, after the words "Victoria the First," of the following: "Or one of the Justice of Peace Courts in Scotland."

The schedule No. 3 may be thus amended, to suit it to the remarks already made on Clause 7 of the draft of $\mathrm{Mr}$. Hawes: "Having ascertained that the following persons, if elected, are willing to act as members of the medical council for [England], I hereby nominate them as fit and proper persons to be returned in that capacity at the ensuing election."

A schedule for the registry of students should be added to those at the end of the draft.

On the whole, the College rejoice in the acknowledgment, that there is much matter of a beneficial description in both of the plans of medical legislation which have been under their consideration. In the comments upon them which they have presumed to offer, the College have kept steadily in view the important principle, that the profession at large is entitled, on the most undeniable grounds of public utility, to a measure of improvement calculated to cunfer equal privileges on all medicul men who are liherally educated, and to enforce a high standard of education upon all, as the condition of obtaining such privileges. In admitting that existing corporate rights can be respected only in 80 far as they are compatible with such a scheme, they have contended, that, in whatever degree they are compatible, they should be amalgamated with the proposed new arrangements, and all that is good in them held sacred. If other medical incorporations and associations will offer their suggestions in a similar spirit, the College have no doubt that the best parts of both schemes may be blended together in such a way as to secure the esactment of a sound and useful measure of medical reform, satisfactory to the profession, and highly beneficial to the public.

\section{PROVINCIAL \\ MEDICAL \& SURGICAL JOURNAL.}

\section{SATURDAY, JANUARY 9, 1841.}

Nor the least valuable among the results of the registration is the prospect afforded of attaining throngh the returns some knowledge of the laws which regulate the development and progress of epidemic disease. We have before had occasion to direct attention to the prevalence of different diseases of this character at different times. The second report of the registrar-general shows, that although various affections belonging to the epidemic class are coexistent at the same time in different localities, there is yet a general rise, prevalence, and decline of each occurring at different times, and apparently following in their progress certain definite laws throughout the whole extent of country embraced in the returns. An additional confirmation is thus afforded to the accuracy of the ancient writers in matters of observation; and the dissertations of Sydenham, on the epidemic constitution of the atmosphere at particular times and seasons, derive fresh interest and importance.
The influence of climate, season, age, sex, temperament, occupation, and local peculiarities of situation, or individual circumstances, is apparent in a great number of diseases. Many of the ills which flesh is heir to are manifestly traceable to the operations of some of these conditions of the human frame, while they are favoured or impeded by the varying nature of others. Epidemics, however, would seem to follow laws of their own, which, though to a certain extent modified by the operations of the ordinary and more appreciable influences of known physical agents, are yet in a measure also independent of them. The returns for 1838 contain information respecting an epidemic of smallpox, which has enabled Mr. Farr to investigate some of the laws by which that disease would seem, in the instance referred to, to have been governed. We have thus obtained valuable data, with which the progress of future epidemics of this and other diseases may be compared, and from which their probable extent and fatality may, in the earlier stages of their course, be prognosticated. At the same time, the agency of several causes formerly supposed to be influential in contributing at least toward the spread of epidemic disease, has been shown in this particular instance to be very questionable. Much diversity of opinion has existed as to the effects of season in limiting or favouring the spread of various epidemics. According to some authorities cold, according to others heat, while, according to a third class, the extremes of either, are concerned to check the progress of diseases usually classed under this head. These opinions, however, have often been advanced on limited or partial observation, or otherwise taken up on insufficient grounds. In the small-pox of 1837-39 we find the deaths registered as follows :-

\begin{tabular}{|c|c|c|c|c|c|c|c|c|c|c|}
\hline \multirow[b]{2}{*}{ Periods ... } & \multicolumn{2}{|c|}{1837.} & \multicolumn{4}{|c|}{1838.} & \multicolumn{4}{|c|}{1839.} \\
\hline & 1 & 2 & 3 & 4 & 5 & 6 & 7 & 8 & 9 & 10 \\
\hline Seasons ... & sr. & Au. & Wr. & Sp. & Sr. & $\mathbf{A u}$ & $\mathbf{W r}$ & Sp. & Sr. & Au. \\
\hline Deaths..... & 2513 & 3289 & $: 242$ & 1489 & 3685 & 3851 & 2982 & 2505 & 1538 & 1730 \\
\hline
\end{tabular}

In this table it will be observed that there is an almost regular increase and decrease from the summer of 1837 to the autumn of 1839 , with the exception of a trifling excess in the autumn of the years 1838 and 1839 orer the corresponding summers of those years. Mr. Earr shows, however, that by taking the mean of the deaths of the several successive periods of the years 18:8 and 1839, a series of numbers is obtained, which corresponds very nearly with the results of a calculation founded upon the supposition, that the decrease in the mortality was at a uniformly accelerated rate. The deaths actually observed in the decline of the epidemic, as compared with those in a regular series, are as follows :-

$\begin{array}{lccccccc} & 1 . & 2 . & 3 . & 4 . & 5 . & 6 . & 7 . \\ \text { Calculated .........4364 } & 4147 & 3767 & 3272 & 2716 & 2156 & 1635 \\ \text { Observed .........4365 } & \frac{4087}{3767} & \frac{3416}{2743} & \frac{2019}{1631} \\ \text { Difference......... } & \frac{16}{1} & \frac{0}{144} & \frac{27}{137} & \frac{1}{4}\end{array}$

These results very closely correspond, and afford a successive decrease of $5,10,15,20,26$, and 32 per cent. The discrepancies between the calculated and the observed numbers may arise from various sources, as many disturbing causes are in operation. Thus, as Mr. Farr remarks, " the rates vary with the density of the population, the numbers susceptible of attack, the mortality, and accidental circumstances; so that to obtain the mean rates applicable to the whole population, or to any portion of the 